\title{
Histologic mimics of malignant melanoma
}

Caroline Bsirini ${ }^{1}$, MD, Bruce R $\underline{\text { Smoller }}^{1}, \mathrm{MD}$

\begin{abstract}
Although spongiotic (eczematous), psoriatic and cutaneous skin infections are among the most common in dermatology consultations, melanocytic lesions - including the different types of nevi and melanomas - are among those that cause a great deal of concern and stress to patients and their clinicians. A diagnosis of benign melanocytic nevus carries a very good prognosis. However, a diagnosis of melanoma might indicate more aggressive treatment, lifelong surveillance and a worse prognosis. Differentiating between these conditions is not always a straightforward process for clinicians and pathologists. Therefore, knowledge of melanoma mimickers is very important for clinicians in general, and dermatologists and pathologists in particular. In this review, we called attention to some of the more frequent benign but unusual melanocytic lesions that are of diagnostic concern for clinicians evaluating these cutaneous proliferations.
\end{abstract}

Keywords: deep penetrating nevus, dysplastic nevus, melanocytic lesions, melanoma, pigmented spindle cell nevus

\section{INTRODUCTION}

Invasive melanoma is the fifth and sixth most frequently diagnosed cancer in men and women, respectively, in the United States. To fight this disease, the diagnostic approach to malignant melanoma has rapidly evolved in the past 25 years. The recent implementation of more defined clinical and histological criteria, with the development of dermoscopy and computer technology, has led to early detection of melanomas and possibly contributed to the increased incidence of diagnosis (annual increase of 2.7\% between 1986 and 2007). ${ }^{(1)}$ However, the misdiagnosis of melanomas (overcalling and undercalling) has also played a significant role in this regard, especially since melanomas can mimic a variety of other benign and malignant neoplasms. In this article, we review melanocytic neoplasms that most closely mimic melanomas, with an emphasis on arriving at the right diagnosis using a combination of clinical and pathological efforts. ${ }^{(1,2)}$

\section{DYSPLASTIC NEVUS}

Dysplastic nevi (atypical nevi) are pigmented lesions with some clinical and histologic features of melanomas. Although dysplastic nevi rarely progress to melanomas, they are considered a major risk factor for melanomas (arising de novo or from any selected nevus). ${ }^{(3,4)}$ They occur in two different clinical contexts: sporadic and familial. Patients with sporadic lesions have a variable number of dysplastic nevi and no family history of melanoma. The prevalence rate of sporadic lesions is $2 \%-8 \%$ in Caucasians, with a melanoma relative risk ranging from 1.6 (95\% confidence interval $[\mathrm{Cl}] 1.4-1.8)$ for subjects with one dysplastic nevus to 10.5 (95\% Cl 5.1-21.8) for subjects with five or more dysplastic nevi. ${ }^{(4)}$ Familial-type dysplastic syndrome was classified by Kraemer as: Type B for individuals with a family history of dysplastic nevi; Type D1 for individuals with numerous dysplastic nevi and a history of melanoma in one family member; and Type D2 for individuals with two or more relatives with a history of melanoma. ${ }^{(5)}$ It has been estimated that familial dysplastic nevus syndrome affects approximately 32,000 individuals in the United States and has an estimated relative risk of $82 \%$ in individuals aged 72 years. ${ }^{(3,6)}$ Clinically, atypical moles are larger $(>0.5 \mathrm{~cm}$ in diameter) than other types of nevi, have irregular and indistinct margins, and exhibit variegated pigmentation. They may be macules, papules or plaques. They are most commonly found on the trunk and extremities but may also develop on other parts of the body. These lesions usually occur in puberty and may continue to appear throughout life. ${ }^{(6)}$

The histologic features of dysplastic nevi include: extension of the junctional component of the nevus beyond the dermal component (shoulder phenomenon); anastomosing, horizontally oriented melanocytic nests with fusion of the adjacent rete ridges; subepidermal lamellar fibroplasia parallel to the epidermis; concentric eosinophilic fibroplasia surrounding melanocytic nests; and lymphohistiocytic inflammatory infiltrate (Fig. 1). Dysplastic nevi also display cytologic atypia, including enlarged melanocytes with increased cytoplasm (ample brown-grey cytoplasm), nuclear pleomorphism, and enlarged nuclei with the presence of prominent nucleoli. ${ }^{(3)}$ Although several studies have focused on grading the degree of dysplasia in dysplastic nevi, this topic is still controversial and subjective. One observational study showed that patients with high-grade dysplasia have an increased risk of melanoma. ${ }^{(7)}$

\section{SPINDLE AND EPITHELIOID CELL (SPITZ) NEVUS}

Spitz nevi are benign melanocytic proliferations that are more frequently present in children and adolescents below 20 years old. These lesions often appear as symmetric, smooth-surfaced, welldefined red- to skin-coloured papules or nodules, and are usually $<1 \mathrm{~cm}$ in diameter. A pigmented variant represents $10 \%$ of these lesions. Spitz nevi can appear on any site, but the most common locations are the face and lower extremities, and they grow rapidly - usually within a few months. ${ }^{(8,9)}$ They are most typically seen as

${ }^{1}$ Department of Pathology and Laboratory Medicine, University of Rochester School of Medicine and Dentistry, Rochester, New York, USA

Correspondence: Dr Bruce Smoller, Professor and Chair, Department of Pathology and Laboratory Medicine, University of Rochester School of Medicine and Dentistry, Rochester, NY 14642, USA. Bruce_Smoller@URMC.Rochester.edu 


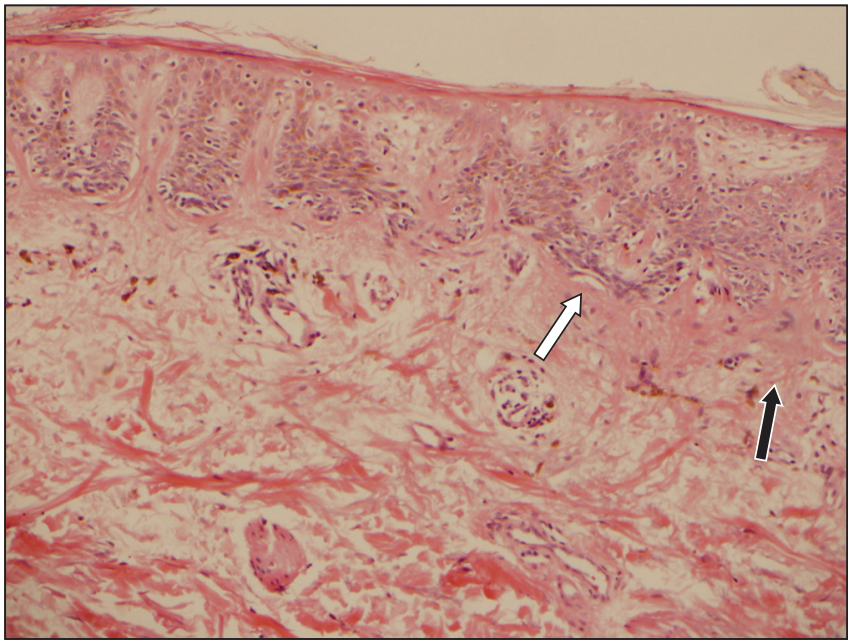

Fig. 1 Photomicrograph of dysplastic nevus shows fusion of the adjacent rete ridges (white arrow) and subepidermal eosinophilic lamellar fibroplasia (black arrow) (Haematoxylin \& eosin, × 100).

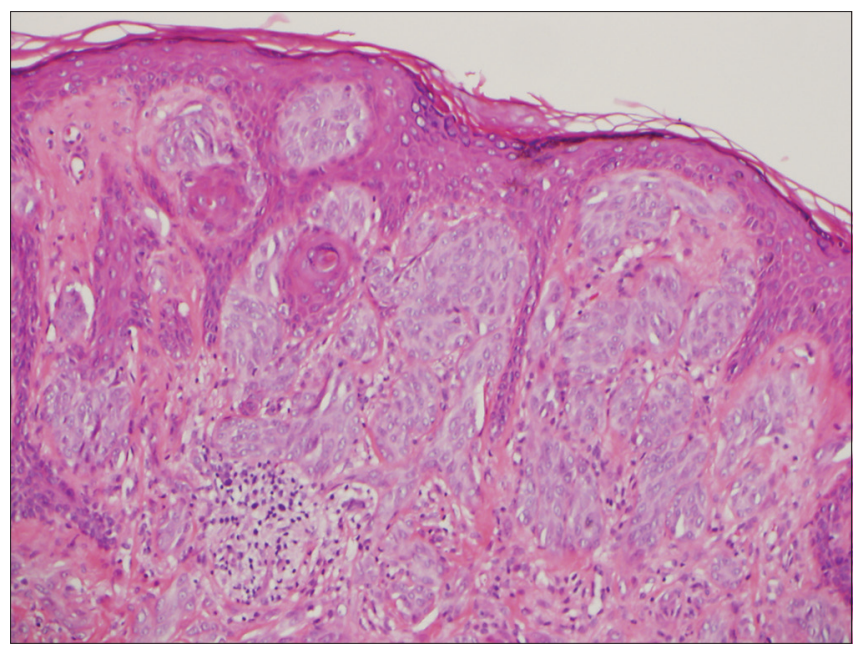

Fig. 2 Photomicrograph of Spitz nevus shows predominantly epithelioid melanocytes at the dermal-epidermal junction, artifactual clefting surrounding nests and maturity with depth (Haematoxylin \& eosin, $\times 100$ ).

solitary lesions; however, multiple Spitz nevus forms have been described in the literature (grouped: more common in children; widespread: more common in adults). Multiple causes have been proposed to explain the eruption of multiple nevi, including but not limited to sunburn, chemotherapy, trauma and Addison's disease; however, the aetiology is still unclear. ${ }^{(10)}$ Clinically, conventional Spitz nevus can be misdiagnosed as haemangioma, angiofibroma, keloid, pyogenic granuloma or xanthogranuloma. ${ }^{(8)}$

Histologically, conventional Spitz nevi can be compound (the most common form), junctional (5\%) or intradermal (10\%-20\%, mainly in adults). ${ }^{(11,12)}$ The characteristic hallmarks of junctional melanocytic nests in Spitz nevi are their architectural symmetry and sharp demarcation. These nests are vertically oriented and have side-to-side uniformity and maturity with depth (transition to smaller nests and single cells with diminished cellular and nuclear size). Other characteristic epidermal features of Spitz nevi include artifactual clefting around the nests, symmetrical epidermal hyperplasia and focal, centrally located pagetoid spread. Although Kamino bodies (eosinophilic globules) can be seen in melanomas, a clear-cut aggregate of these globules is more suggestive of Spitz nevi. ${ }^{(8,9)}$ Cytomorphologically, the melanocytes are epithelioid and/or spindled, and contain abundant eosinophilic cytoplasm, vesicular nuclei and prominent nucleoli with only occasional pleomorphism in a minority of cells (Fig. 2). ${ }^{(8,9)}$

The presence of a disordered architecture and overt atypia is evidence against a traditional Spitz nevus and raises concerns of an atypical Spitzoid nevus or even melanoma. ${ }^{(8)}$ Atypical Spitzoid nevi are borderline melanocytic proliferations that are associated with minimal lethal potential, minimal melanoma risk and moderate risk of local node metastasis. However, these lymph node deposits, if present, are usually small and subcapsular, resemble the primary lesion and lack malignant features. ${ }^{(13)}$ They occur at a slightly older age than traditional Spitz nevi; however, due to the high degree of overlap, this feature is not useful as a diagnostic criterion. ${ }^{(8)}$ The size of the atypical Spitzoid nevi is usually $>1 \mathrm{~cm}$. They display haphazard infiltration with extension into the subcutis, asymmetry, poor circumscription, ulceration, rare or absent Kamino bodies, prominent pagetoid spread, a lack of both junctional clefting around the nests and maturation in the dermis, and mitotic rates $>2-6 / \mathrm{mm}^{2}$ (as compared with $<2 / \mathrm{mm}^{2}$ for conventional Spitz nevus). Cytomorphologically, the melanocytes show more heterogeneous cell types, granular cytoplasm, an increased nuclear-to-cytoplasmic ratio, hyperchromatism and prominent large cytoplasm. ${ }^{(8,9,13,14)}$

In contrast to the pattern of staining seen with $\mathrm{HMB}-45$, both S100 and MART-1 show strong and diffuse positivity throughout Spitz tumours (similar staining pattern with melanomas). Ki-67 demonstrates only slight proliferative activity at the surface of the lesion. ${ }^{(9)}$ Several studies have suggested that the presence of homozygous 9p21 deletions in Spitz tumours correlates with a poor outcome and higher risk of developing tumour extension beyond the lymph nodes. ${ }^{(13)}$

\section{PIGMENTED SPINDLE CELL NEVUS (REED NEVUS)}

Pigmented spindle cell nevus, a benign, heavily pigmented lesion, is considered a variant of Spitz nevus. It is more commonly seen in young adults (average age 22 years; range 3-54 years), has a female predominance (male-to-female ratio 1:4.5), and typically presents on the lower extremities and trunk. The lesions are small $(<7 \mathrm{~mm})$ dark brown-to-black papules or plaques with regular, distinct borders. ${ }^{(15)}$

Histologically, pigmented spindle cell nevi are composed of large, heavily pigmented and vertically oriented junctional and/or compound melanocytic nests that display sharp lateral demarcation with central pagetoid spread, epidermal hyperplasia, dermal inflammation and adnexal extension (Fig. 3). Cytologically, the cells are pigmented, spindle-shaped and uniform throughout the lesion. They lack diffuse or severe cytologic atypia, and have hyperchromatic nuclei and occasional nucleoli with prominent melanin pigmentation. Rare junctional or dermal mitotic figures $\left(<2 / \mathrm{mm}^{2}\right)$ can also be identified. ${ }^{(15)}$ The dark colour, as well as 


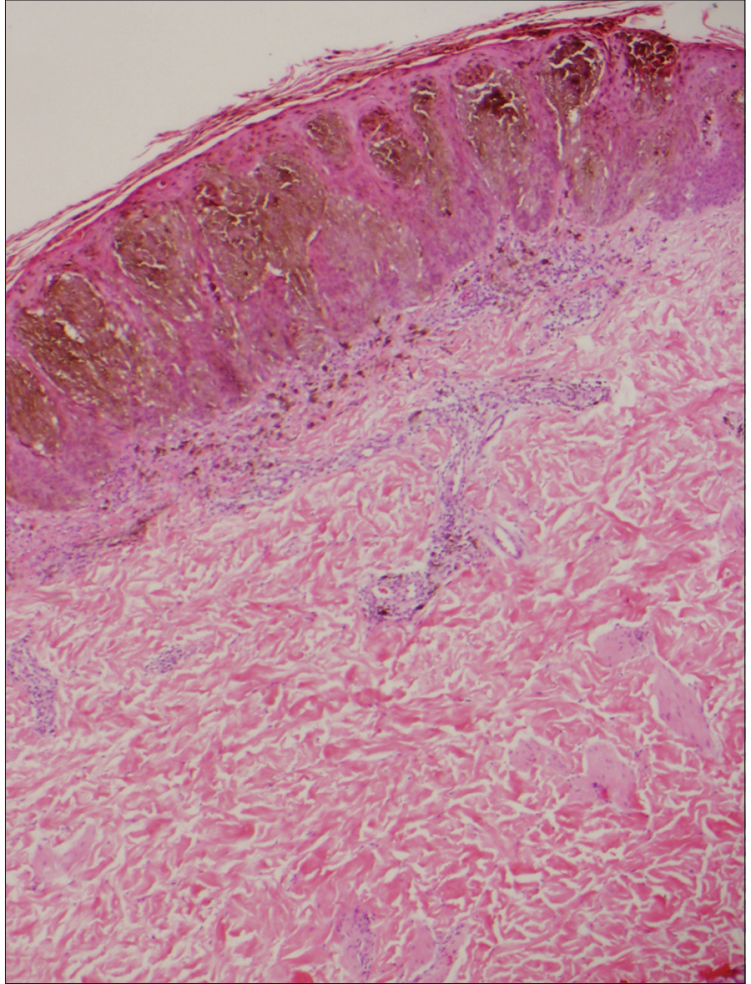

Fig. 3 Photomicrograph of pigmented spindle cell nevus shows mainly junctional, uniform and heavily pigmented melanocytes with dermal inflammation (Haematoxylin \& eosin, $\times 40$ ).

the presence of atypical histopathologic features and some rare atypical presentations (e.g. irregular margins, colour variation, asymmetrical appearance and cytologic atypia) make melanoma high on the differential diagnosis list. ${ }^{(15-18)}$

\section{CELLULAR BLUE NEVUS}

Cellular blue nevus (CBN), a cellular variant of blue nevus, has benign behaviour with few recurrent cases and involvement of the regional lymph nodes. ${ }^{(19,20)}$ It presents as a small, intensely pigmented, dark blue/black dome-shaped nodule $(0.5-1 \mathrm{~cm})$ in adults (usually $<40$ years), with a slight female predominance. Occasionally, larger lesions have been documented in the literature. The most common locations of these nevi are the buttocks and sacrococcygeal areas, followed by the scalp and extremities. Besides these typical locations, an intramucosal location of $\mathrm{CBN}$ has also been described in male and female genital tracts, as well as the orbit. ${ }^{(20)}$

Histologically, a characteristic feature of $C B N$ is its biphasic tumour pattern, which is composed of a conventional blue nevus component (densely pigmented dendritic cells) surrounding or, less likely, admixed with a highly cellular component (amelanotic oval to spindle cells), occupying the mid-to-lower dermis and extending into the subcutis with pushing borders (Fig. 4). The epidermis overlying the lesion is usually uninvolved. Sclerosis, multinucleated giant cells, fasciculation and neuroid structures are also common findings associated with this lesion. ${ }^{(20,21)}$ It is critical to be aware of the possible degenerative changes that can occur with this lesion (e.g. haemorrhage, myxoid degeneration and hyalinisation) to

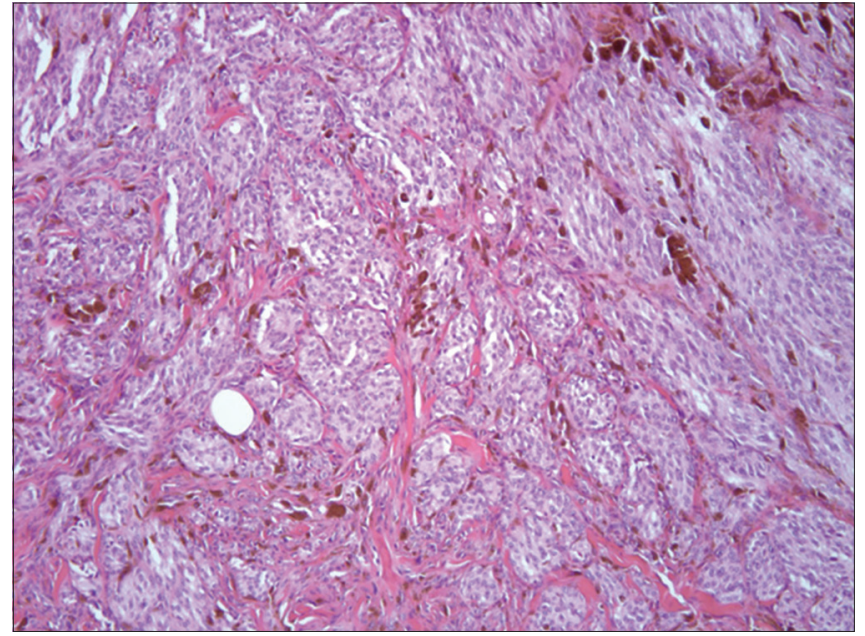

Fig. 4 Photomicrograph of cellular blue nevus shows nested and relatively uniform oval melanocytes admixed with heavily pigmented dendritic cells and melanophages. Thickened and trapped collagen bundles are also identified between the nests (Haematoxylin \& eosin, $\times 200$ ).

avoid misinterpreting these findings as tumour necrosis, which is typically absent in CBN. Cytologically, this lesion lacks overt atypia, pleomorphism, atypical mitoses, high mitotic activity (usually $<1 / \mathrm{mm}^{2}$ is observed), and the nuclei display vesicular chromatin and occasional nucleoli. ${ }^{(20)}$

Atypical CBN is the term used to describe some rare cases of $\mathrm{CBN}$ that show architectural and/or cytologic atypia but not to the extent of being malignant. ${ }^{(20)}$ There is a lot of confusion and controversy around this term, with no consensus regarding the classification for $\mathrm{CBN}$, atypical $\mathrm{CBN}$ and malignant blue nevus. ${ }^{(22,23)}$

Malignant blue nevus is an aggressive form of melanoma that typically arises in the background of a blue nevus or CBN, and is associated with metastasis and death. This tumour is more commonly seen on the scalp and in older patients, and it has a slight male predominance. The presence of a benign blue nevus component or $\mathrm{CBN}$ is identified in most cases that have adequate sampling. Microscopically, the presence of nuclear pleomorphism, cytologic atypia, numerous atypical mitoses $\left(>3 / \mathrm{mm}^{2}\right)$, necrosis and destructive invasion are the most specific features of malignancy. ${ }^{(20)}$

\section{DEEP PENETRATING NEVUS}

Deep penetrating nevus (also known as plexiform spindle cell nevus, a term used by Barnhill et al) ${ }^{(24)}$ is a benign variant of melanocytic nevus. The clinical presentations are fairly similar to those of $\mathrm{CBN}$ : heavily pigmented blue/black dome-shaped nodules or papules $<1 \mathrm{~cm}$ in diameter; younger patients (typically $<40$ years of age); and a female predominance. However, the most common location for these lesions is the face, followed by the trunk and upper extremities. ${ }^{(25)}$

Histologically, deep penetrating nevus is a symmetrical, well-demarcated and pigmented dermal lesion with greater depth than width. As its name implies, the dermal component penetrates deep into the dermis and subcutaneous fat, tracking around the adnexa, vessels and nerves in a plexiform and 
non-destructive pattern. Infiltration of the arrector pili muscle can also occur. The epidermis overlying the nevus typically lacks a pagetoid spread and displays minimal or no junctional component. If present, the junctional component is discrete, inconspicuous and well demarcated. The dermal component in the reticular dermis is more cellular, and consists of vertically oriented epithelioid and spindle-shaped melanocytes with sparse to abundant heavily pigmented melanophages and mild lymphocytic infiltrate (Fig. 5). The papillary dermis is usually spared unless a common acquired nevus is present and occupying the most superficial part of the lesion, which is commonly associated with deep penetrating nevi. ${ }^{(25,26)}$ At a higher magnification, the pigmented melanocytes have abundant and plump cytoplasm, hyperchromatic nuclei and small, inconspicuous nucleoli. Nuclear pseudoinclusions can also be observed. Mild cytologic atypia and nuclear pleomorphism are usually focally present. Mitoses, though rare, may also be present $\left(0-1.2 / \mathrm{mm}^{2}\right)$. Both mitoses and nuclear pleomorphism may be present even in the deeper parts of the lesion. The apparent lack of maturation surrounding the adnexa and the presence of atypia and pleomorphism in this lesion are potential pitfalls that may lead to a misdiagnosis of malignant melanoma. However, the overall architecture and cytologic picture of symmetry, non-destructive adnexal involvement, nevus cell maturation in areas away from hair follicles, lack of necrosis, mild atypia, random focal pleomorphism and rare mitoses point towards the right diagnosis. ${ }^{(25-29)}$

\section{ACRAL NEVUS}

Acral nevi are melanocytic nevi that involve acral skin (palms, soles and nail beds). They occur in $4 \%-9 \%$ of the population. These lesions are usually small $(<6 \mathrm{~mm}$ in diameter), wellcircumscribed pigmented macules. ${ }^{(30)}$ Several studies have suggested that a plantar nevus $>7 \mathrm{~mm}$ in diameter is more likely to be a melanoma than an acral nevus. ${ }^{(31)}$ The special location of these nevi, with their pattern of crests and furrows on the palms and soles, gives them some unusual gross and histologic features that differ from nevi present elsewhere.

To evaluate for symmetry and circumscription in acral nevi, a section plane that is perpendicular to the furrows and crests is recommended. ${ }^{(32)}$ These nevi are compound or junctional, and consist of a proliferation of melanocytic nests and single melanocytes along the dermal-epidermal junction. Lesions that are $<2-3 \mathrm{~mm}$ in diameter tend to have more single melanocytes than nests. Otherwise, melanocytic nests predominate in these nevi. The melanocytic nests are typically small, well demarcated from the adjacent keratinocytes and symmetrically distributed (Fig. 6). Melanin pigment is often present as vertical columns within the stratum corneum, and pagetoid spread may be seen throughout the entire thickness of the epidermis. The intradermal component (if present) has a benign and mature appearance. Cytologically, the melanocytes are small and round, and may possess short, thin and prominent dendrites that are of the same length throughout the lesion. Occasionally, atypical melanocytes may also be present. The most important differential diagnosis for acral nevus is acral lentiginous melanoma in situ (Box 1). ${ }^{(30-33)}$

\section{RECURRENT NEVUS}

Recurrent nevus is a benign pigmented melanocytic proliferation that develops at the site of a previously excised nevus, or following trauma or chronic irritation. These nevi tend to occur on the trunk (the back being the most common site), followed by the face and extremities in young female patients ( $<40$ years). ${ }^{(34)}$ Most of these nevi arise from common acquired nevi (mostly compound) and, less commonly, from dysplastic, congenital and Spitz nevi, with an average time to recurrence of six months after the initial biopsy. ${ }^{(35)}$ The possible pathogenesis of these nevi is controversial, with multiple theories suggested such as repopulation from remaining adnexal structures, residual intradermal nevi or adjacent epidermis. ${ }^{(34-36)}$ Clinically, they appear as variably pigmented macular areas with irregular borders occurring within a scar, and are potentially a concern for malignancy if a history of prior trauma at the site is unknown. ${ }^{(37)}$

A trizonal histologic pattern, consisting of a scar, junctional melanocytic proliferation and residual dermal melanocytes, has been described (Fig. 7). ${ }^{(36)}$ Malignant melanoma with regression is a major pitfall of this entity. The overlapping histologic features include epidermal pagetoid spread, irregularly distributed melanocytic nests and single melanocytes overlying the dermal scar, as well as adnexal spread, cytologic atypia and dermal lymphocytic response. However, in recurrent nevi, the pagetoid spread is usually confined and does not extend beyond the scar, the atypical melanocytes are confined to the epidermis, and mitoses are usually rare. ${ }^{(34,35,37,38)}$ Immunohistochemical staining (HMB-45, tyrosinase and Ki67) has been shown to be helpful in difficult cases. Ki67 usually displays a low proliferation rate, while HMB-45 and tyrosinase tend to lose expression with increasing depth. ${ }^{(36)}$ In the end, correlation with clinical history and previous biopsies is of great importance in identifying this entity. ${ }^{(35)}$

\section{CONCLUSION}

Melanoma is an aggressive tumour with high incidence and mortality rates, and the potential to metastasise to any organ. Melanoma mimickers, including but not limited to the discussed melanocytic entities, are benign neoplasms that both the clinician and pathologist should be aware of in order to avoid a misdiagnosis of melanoma. Accurate diagnosis entails clinicpathologic correlation. Attention to growth patterns such as circumscription, symmetry and pushing margins - as opposed to asymmetry, lack of sharp borders and infiltrative margins helps to indicate a benign diagnosis. Cytologic features such as increased or atypical mitoses, cellular pleomorphism and necrosis favour a diagnosis of melanoma. It is important for pathologists to be aware of these relatively uncommon subtypes of benign melanocytic proliferations so as to prevent overdiagnosis of melanoma and the resultant additional surgical procedures, chemotherapeutic interventions and emotional trauma. 

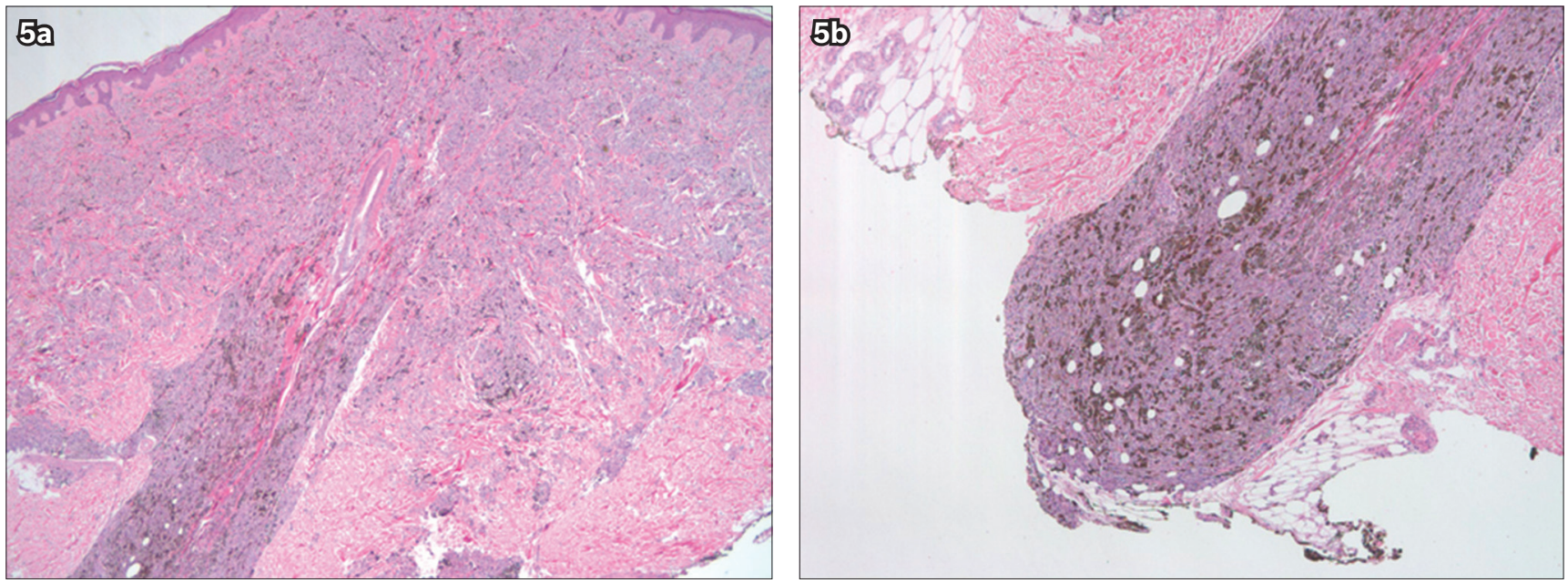

Fig. 5 Photomicrographs of deep penetrating nevus show (a) dermally located nevus penetrating around a hair follicle without destructing it; (b) the characteristic deep penetration with pushing borders (Haematoxylin \& eosin, $\times 40$ ).

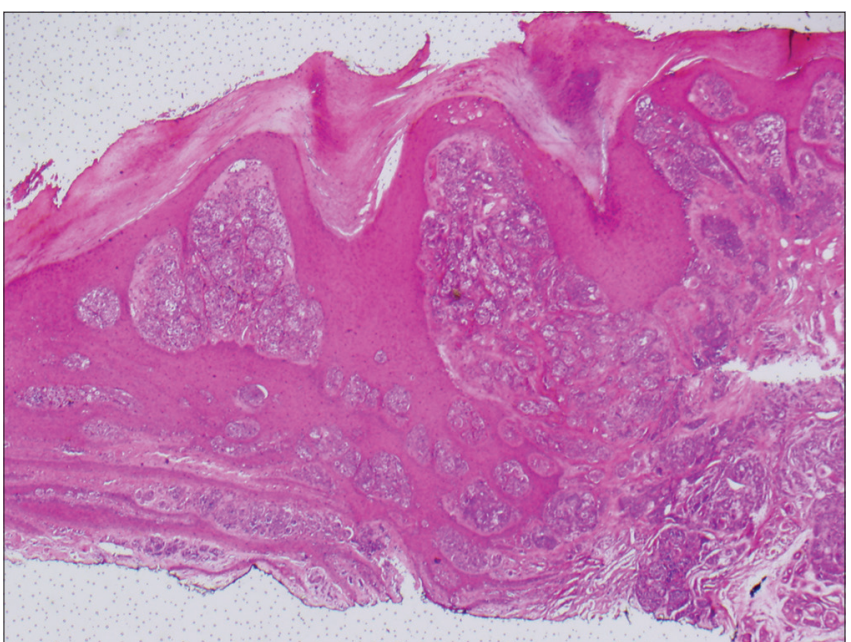

Fig. 6 Photomicrograph of acral nevus shows junctional melanocytic nests and the characteristic hyperkeratosis seen at these sites (Haematoxylin $\&$ eosin, $\times 100)$.

\begin{tabular}{|c|c|}
\hline Acral nevus & Acral lentiginous melanoma \\
\hline - Melanocytic nests predominate & - Mostly single melanocytes \\
\hline $\begin{array}{l}\text { - Pigment in column above the } \\
\text { furrow }\end{array}$ & $\begin{array}{l}\text { - Diffuse pigment throughout } \\
\text { the stratum corneum }\end{array}$ \\
\hline - Short and even dendrites & - Long and uneven dendrites \\
\hline - Minimal cytologic atypia & - Clear cytologic atypia \\
\hline - Sharply circumscribed & - Poorly circumscribed \\
\hline - Pagetoid spread & - Pagetoid spread \\
\hline
\end{tabular}

\section{REFERENCES}

1. Rigel DS, Russak J, Friedman R. The evolution of melanoma diagnosis: 25 years beyond the ABCDs. CA Cancer J Clin 2010; 60:301-16.

2. Weyers $\mathrm{W}$. The 'epidemic' of melanoma between under- and overdiagnosis. J Cutan Pathol 2012; 39:9-16.

3. Clarke LE. Dysplastic nevi. Clin Lab Med 2011; 31:255-65.

4. Goldstein AM, Tucker MA. Dysplastic nevi and melanoma. Cancer Epidemiol Biomarkers Prev 2013; 22:528-32.

5. Kraemer $\mathrm{KH}$, Greene $\mathrm{MH}$, Tarone $\mathrm{R}$, et al. Dysplastic naevi and cutaneous melanoma risk. Lancet 1983; 2:1076-7.

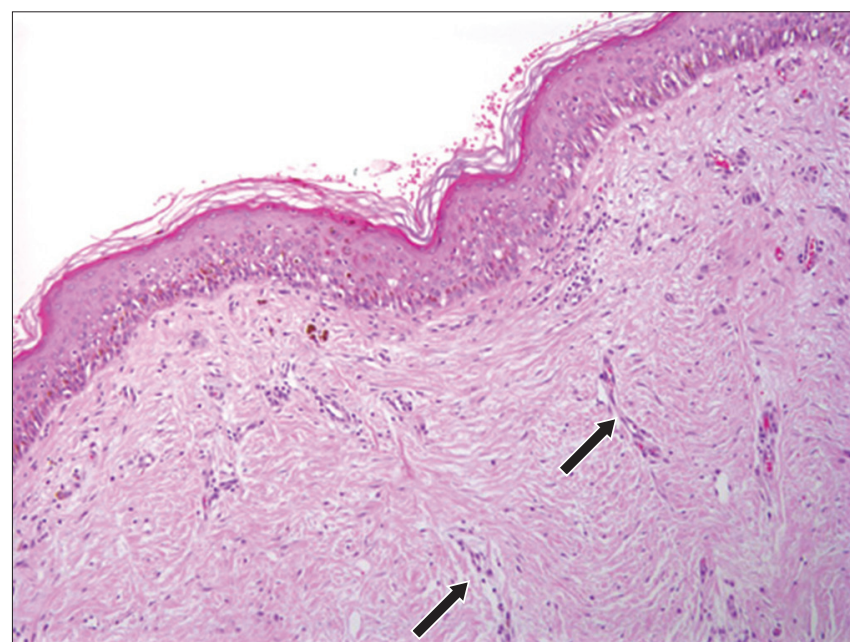

Fig. 7 Photomicrograph of recurrent nevus shows single junctional melanocytes and dermal melanophages overlying a dermal scar with vertically oriented vessels (black arrows) (Haematoxylin \& eosin, $\times 100$ ).

6. Silva JH, Sá BC, Avila AL, Landman G, Duprat Neto JP. Atypical mole syndrome and dysplastic nevi: identification of populations at risk for developing melanoma - review article. Clinics (Sao Paulo) 2011; 66:493-9.

7. Arumi-Uria M, McNutt NS, Finnerty B. Grading of atypia in nevi: correlation with melanoma risk. Mod Pathol 2003; 16:764-71.

8. Luo S, Sepehr A, Tsao H. Spitz nevi and other Spitzoid lesions part I. Background and diagnoses. J Am Acad Dermatol 2011; 65:1073-84.

9. Barnhill RL. The Spitzoid lesion: rethinking Spitz tumors, atypical variants, 'Spitzoid melanoma' and risk assessment. Mod Pathol 2006; 19 Suppl 2:S21-33.

10. Dawe RS, Wainwright NJ, Evans AT, Lowe JG. Multiple widespread eruptive Spitz naevi. Br J Dermatol 1998; 138:872-4

11. Weedon D, Little JH. Spindle and epithelioid cell nevi in children and adults. A review of 211 cases of the Spitz nevus. Cancer 1977; 40:217-25.

12. Kapur P, Selim MA, Roy LC, et al. Spitz nevi and atypical Spitz nevi/tumors: a histologic and immunohistochemical analysis. Mod Pathol 2005; 18:197-204.

13. Harms KL, Lowe L, Fullen DR, Harms PW. Atypical Spitz tumors: a diagnostic challenge. Arch Pathol Lab Med 2015; 139:1263-70.

14. Ferrara G, Argenziano G, Soyer HP, et al. The spectrum of Spitz nevi: a clinicopathologic study of 83 cases. Arch Dermatol 2005; 141:1381-7.

15. Aung PP, Mutyambizi KK, Danialan R, Ivan D, Prieto VG. Differential diagnosis of heavily pigmented melanocytic lesions: challenges and diagnostic approach. J Clin Pathol 2015; 68:963-70.

16. Boneti KK, Piñeiro-Maceira J, Pereira FB, Barcaui CB. Reed nevus (pigmented spindle-cell nevus): a report of three cases with distinct dermoscopic patterns. An Bras Dermatol 2010; 85:531-6.

17. Maurichi A, Baldi M, Bartoli C, et al. Pigmented spindle-cell nevus: a melanoma simulator. Dermatol Online J 2004; 10:5 
18. Seregard S. Pigmented spindle cell naevus of reed presenting in the conjunctiva. Acta Ophthalmol Scand 2000; 78:104-6.

19. Misago N, Nagase K, Toda S, et al. Cellular blue nevus with nevus cells in a sentinel lymph node. Eur J Dermatol 2008; 18:586-9.

20. Zembowicz A, Phadke PA. Blue nevi and variants: an update. Arch Pathol Lab Med 2011; 135:327-36.

21. Bhawan J, Chang WH, Edelstein LM. Cellular blue nevus. An ultrastructural study. J Cutan Pathol 1980; 7:109-22.

22. Jonjić N, Dekanić A, Glavan N, Prpić-Massari L, Grahovac B. Cellular blue nevus diagnosed following excision of melanoma: a challenge in diagnosis. Case Rep Pathol 2016; 2016:8107671.

23. Barnhill RL, Argenyi Z, Berwick M, et al. Atypical cellular blue nevi (cellular blue nevi with atypical features): lack of consensus for diagnosis and distinction from cellular blue nevi and malignant melanoma ("malignant blue nevus"). Am J Surg Pathol 2008; 32:36-44.

24. Barnhill RL, Mihm MC Jr, Magro CM. Plexiform spindle cell naevus: a distinctive variant of plexiform melanocytic naevus. Histopathology 1991; 18:243-7.

25. Luzar B, Calonje E. Deep penetrating nevus: a review. Arch Pathol Lab Med $2011 ; 135: 321-6$.

26. Strazzula L, Senna MM, Yasuda M, Belazarian L. The deep penetrating nevus. J Am Acad Dermatol 2014; 71:1234-40.

27. Flauta VS, Lingamfelter DC, Dang LM, Lankachandra KM. Deep penetrating nevus: a case report and brief literature review. Diagn Pathol 2006; 1:31.

28. Gupta A, Srilatha PS, Suvarna N, Rao L. Deep penetrating nevus: a distinct variant of melanocytic nevus. Indian J Pathol Microbiol 2011; 54:156-7.

29. Mehregan DA, Mehregan AH. Deep penetrating nevus. Arch Dermatol 1993; 129:328-31.

30. Elder DE. Precursors to melanoma and their mimics: nevi of special sites. Mod Pathol 2006; 19 Suppl 2:S4-20.

31. Palicka GA, Rhodes AR. Acral melanocytic nevi: prevalence and distribution of gross morphologic features in white and black adults. Arch Dermatol 2010; 146:1085-94.

32. Bravo Puccio F, Chian C. Acral junctional nevus versus acral lentiginous melanoma in situ: a differential diagnosis that should be based on clinicopathologic correlation. Arch Pathol Lab Med 2011; 135:847-52.

33. Ahn CS, Guerra A, Sangüeza OP. Melanocytic nevi of special sites. Am J Dermatopathol 2016; 38:867-81.

34. Fox JC, Reed JA, Shea CR. The recurrent nevus phenomenon: a history of challenge, controversy, and discovery. Arch Pathol Lab Med 2011; 135:842-6.

35. King R, Hayzen BA, Page RN, et al. Recurrent nevus phenomenon: a clinicopathologic study of 357 cases and histologic comparison with melanoma with regression. Mod Pathol 2009; 22:611-7.

36. Hoang MP, Prieto VG, Burchette JL, Shea CR. Recurrent melanocytic nevus: a histologic and immunohistochemical evaluation. J Cutan Pathol 2001; 28:400-6.

37. Kornberg R, Ackerman AB. Pseudomelanoma: recurrent melanocytic nevus following partial surgical removal. Arch Dermatol 1975; 111:1588-90.

38. Tschandl P. Recurrent nevi: report of three cases with dermatoscopicdermatopathologic correlation. Dermatol Pract Concept 2013; 3:29-32. 